\title{
Direct comparison of CMR dobutamine stress wall motion and perfusion analysis with adenosine perfusion in patients after bypass surgery
}

\author{
Christoph Klein ${ }^{1 *}$, Rolf Gebker', Sebastian Kelle ${ }^{1}$, Kristof Graf', Stephan Dreysse' ${ }^{1}$ Bernhard Schnackenburg², \\ Eckart Fleck ${ }^{1}$
}

From 2011 SCMR/Euro CMR Joint Scientific Sessions

Nice, France. 3-6 February 2011

\section{Introduction}

Dobutamine and adenosine stress are the two methods most often used in CMR for the diagnosis of ischemia. Both methods have demonstrated good results in patients after coronary artery bypass graft (CABG). However, a direct comparison has not been examined.

\section{Purpose}

Comparison of the diagnostic accuracy of dobutamine wall motion analysis (DSMR) and perfusion (DSPERF) with adenosine perfusion (APERF)

\section{Methods}

One hundred nine patients (93 men, $65 \pm 8$ years, BMI $28.7 \pm 3.3$ ) after $C A B G$ underwent CMR imaging on two appointments. 1) LV-function, DSMR (10-40 $\mu \mathrm{g} / \mathrm{kg} / \mathrm{min}$ $+2 \mathrm{mg}$ atropine if needed until target heart rate) imaging (SSFP) of 3 short axis (apical, medial, basal) and 3 long axis views at each stress level. Perfusion imaging of 3 short axis (SSFP, TR/TE $2.8 \mathrm{~ms} / 1.4 \mathrm{~ms}$, FA $50^{\circ}$, SENSE-factor 3.0 ) were acquired every second heart beat during dobutamine stress at maximal stress level with a contrast bolus of $0.1 \mathrm{mmol} / \mathrm{kg}$ Gd-DTPA. Late gadolinium enhancement (LGE) imaging (3D inversion recovery technique, TE/TR 2.8/6.6, FA $15^{\circ}$ ) $10 \mathrm{~min}$ after additional $0.1 \mathrm{mmol} / \mathrm{kg}$ Gd-DTPA. 2) Adenosine and rest perfusion $(140 \mu \mathrm{g} / \mathrm{min} / \mathrm{kg}$ body weight $)$ (SSFP, TE/TR 2.7/1.4, FA 50 3 slices per heart beat) using a $0.05 \mathrm{mmol} / \mathrm{kg}$ contrast bolus of Gd-DTPA. Images were analyzed visually using the standard 16 segment model. A developing wall motion abnormality

${ }^{1}$ German Heart Institute Berlin, Berlin, Germany

Full list of author information is available at the end of the article
Table 1 Diagnostic accuracy

\begin{tabular}{llll}
\hline & Sensitivity & Seceficity & Diagnostic accuracy \\
\hline DSMR & $88 \%$ & $96 \%$ & $93 \%$ \\
DSPERF & $86 \%$ & $73 \%$ & $79 \%$ \\
DSMR + DSPERF & $95 \%$ & $73 \%$ & $83 \%$ \\
APERF & $75 \%$ & $91 \%$ & $85 \%$ \\
\hline
\end{tabular}

or stress induced perfusion defect (larger, if LGE is present) in $>1$ segment was defined as pathological. Invasive coronary angiography served as the reverence. Significant stenosis was defined as $>50 \%$ in a bypass graft or a native vessel $>2 \mathrm{~mm}$ diameter in areas without $>75 \%$ transmural LGE.

\section{Results}

Prevalence of angiographically significant stenosis was in $63 \%$ of patients. Surgery was performed $9.5 \pm 6.6$ years before CMR. Stent placement after CABG was performed in 68 patients. Ejection fraction was $48 \pm 8 \%$. LGE was present in $68 \%$ of patients. Sensitivity, specificity and diagnostic accuracy are shown in table 1. Figure 1.

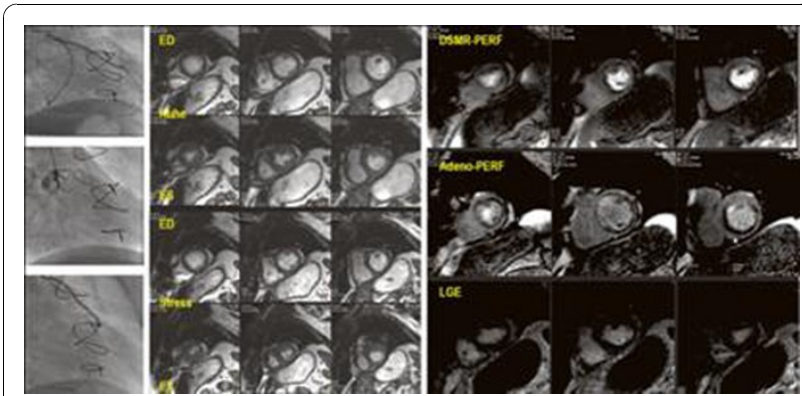

Figure 1

(c) 2011 Klein et al; licensee BioMed Central Ltd. This is an open access article distributed under the terms of the Creative Commons Attribution License (http://creativecommons.org/licenses/by/2.0), which permits unrestricted use, distribution, and reproduction in any medium, provided the original work is properly cited. 


\section{Conclusions}

DSMR was the best test for the detection of ischemia in patients after bypass surgery and outperforms adenosine stress perfusion. The addition of DSMR perfusion increases sensitivity, but decreases diagnostic accuracy.

Caption for image: Angiographically ischemia in the inferior and lateral wall. Wall motion abnormalities in the lateral wall. Perfusion defect (dobutamine and adenosine) is larger extending to the inferior wall and apical anterior. No LGE present.

\section{Author details}

${ }^{1}$ German Heart Institute Berlin, Berlin, Germany. ${ }^{2}$ Philips Clinical Science, Hamburg, Germany.

Published: 2 February 2011

doi:10.1186/1532-429X-13-S1-P100

Cite this article as: Klein et al:: Direct comparison of CMR dobutamine stress wall motion and perfusion analysis with adenosine perfusion in patients after bypass surgery. Journal of Cardiovascular Magnetic

Resonance 2011 13(Suppl 1):P100.

Submit your next manuscript to BioMed Central and take full advantage of:

- Convenient online submission

- Thorough peer review

- No space constraints or color figure charges

- Immediate publication on acceptance

- Inclusion in PubMed, CAS, Scopus and Google Scholar

- Research which is freely available for redistribution

Submit your manuscript at www.biomedcentral.com/submit
C Biomed Central 